\title{
The Entrepreneurial Network Simulation Model for the Supporting System of Management Decisions Making at a Municipal Level
}

\author{
Dmitry B. Berg, a), Anastasiya V. Apanasenko ${ }^{1, \text { b) }}$, Marina A. Medvedeva ${ }^{1, \mathrm{c})}$, \\ Silvia S. Parusheva ${ }^{2, d)}$ \\ ${ }^{1}$ Ural Federal University, Mira 19, Ekaterinburg, Russia, 620002 \\ ${ }^{2}$ Varna University of Economics, 9002 Varna, Bulgaria \\ a)bergd@mail.ru \\ b)stacy-chan@yandex.ru \\ ${ }^{c}$ Corresponding author: marmed55@yandex.ru \\ d)parusheva@ue-varna.bg
}

\begin{abstract}
The article deals with a system dynamic model implemented in the AnyLogic simulation environment. It gives proof of its advantages concerning the municipality entrepreneurial network model, which was previously realised in Powersim environment. It also formulates the prospects of this investigation development. This is the working out of an information support system of management decisions making based on a java-application. Such an application can be obtained by the simulation model exporting to java-code by means of AnyLogic. Data warehouses, interfaces and other applications can be integrated with this application. The system obtained in this way will become even a more effective tool for the management decisions making support.
\end{abstract}

\section{INTRODUCTION}

Simulation modeling is one of the most effective and universal methodologies for complex systems studying. A special case of simulation modeling is system dynamics. It was offered by the American scientist Jey Forrester in the 1950s [1]. Such an approach makes it possible to identify causal relationships between objects and phenomena in a better way. It is especially important when studying complex economic systems. Entrepreneurial networks, associations of legal entities for achieving mutual socio-economic goals, are an example of such systems [2]. Thus, the simulation system dynamic model is an effective tool [3 - 8] and may be used in decision-making support for network interaction management at a municipal level. The model allows you to retrace the status of communications and exchanges at different time intervals with different initial conditions and provides visual interface.

\section{ENTERPRISE NETWORK SIMULATION MODEL IN ANYLOGIC}

The object of this investigation is the municipality entrepreneurial network. The network consists of five network partners. Four of them are industrial associations (crop production and animal husbandry, food industry, services, population), and the fifth one is the external environment. All links between network partners are mutually directed, i.e. each member of the network buys the production of other members. The system dynamic model in Powersim has already been created for this network [9]. In the frames of this investigation, an improved version of that model has been implemented in AnyLogic. This modeling environment was chosen because it provides more opportunities in comparison with others, in particular, export in the form of java-applications. 
When creating a new version, several changes have been made to the model. A data entry interface has been added for the user's input data and the model parameters adjustment. On it there is a group of text fields in the form of mutual commodity-money exchange matrix. The matrix dimension corresponds to the number of network partners. The matrix is already filled with planned values. They are obtained from consumer basket analysis of municipality residents [4]. These values are easy to be changed by the user. This greatly simplifies the conduction of simulation experiments with various input data. In a real entrepreneurial network, the actual output and products consumption may differ from the planned one. To model its activity, an element of randomness has been introduced in these indicators calculations. This allows you to simulate the entrepreneurial network functioning over a long period on the basis of a small amount of the given data. Besides there is a switch on the form regulating the use of inside money in the entrepreneurial network. This is the main model parameter control. If its value is "false", inside money is not used, and if it is "true", it is used.

The cause-effect relationships diagram became more compact and accurate without losing its visibility. All elements of the model are grouped in six logical blocks. Four of them correspond to network partners, one corresponds to the external environment. The sixth block (exchange control regulator) combines the resulting indicators calculation and the model parameters control. Intermediate variables connections with the resultant ones are hidden. AnyLogic, in contrast to Powersim, makes it possible not to display the connections between elements. This allowed to move the calculation block of the resulting indicators to the centre of the diagram and get rid of variables copies. The updated chart is shown in Fig. 1:

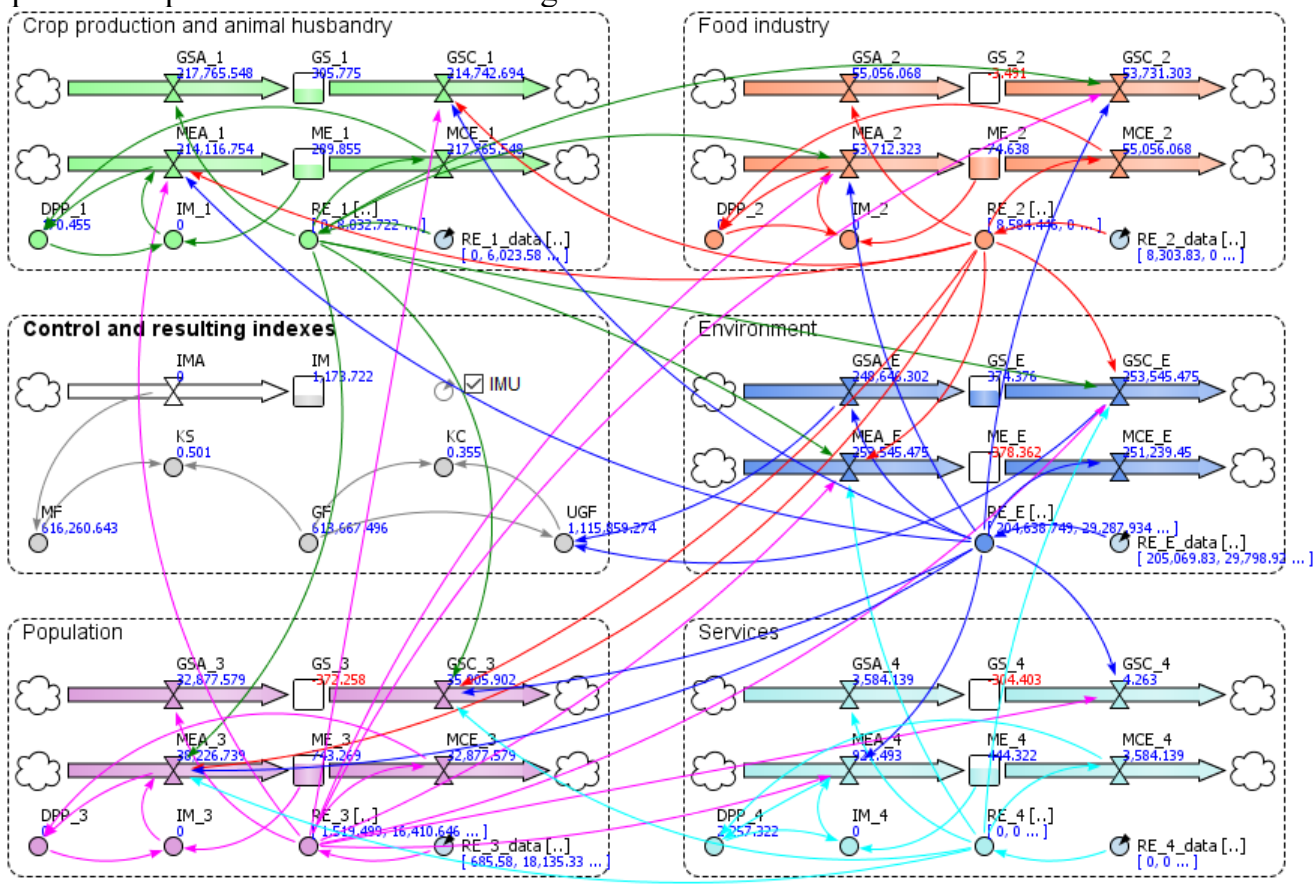

FIGURE 1. Diagram of the causal relationships of the system dynamic model.

The method of calculating the amount of inside money is changed. In the previous version of the model, each network partner received at the current step as many additional means of payment as its deficit was at the previous step. In this case, if every current step also turns out to be unprofitable, then the amount of cash does not rise above zero. With the new method of calculation, the network partner receives additionally as much inside money as he owes at the previous step and owes at the current one. Thus, the amount of money can only be less than zero at the first step of simulation. This reflects the specifics of inside money use more accurately.

The equations of the basic elements of the obtained model are given in the general form. They reflect the interrelation between various indicators of the municipality entrepreneurial network functioning, commodity and cash flows between them:

1. Vector of mutual exchange $\left(R E_{-} K\right)$ :

$$
R E_{-} K(t)=\left\{R E_{-} \bar{K}_{1}^{k}(t), R E_{-} K_{2}^{k}(t), R E_{-} K_{3}^{k}(t), R E_{-} K_{4}^{k}(t), R E_{-} K_{5}^{k}(t)\right\},
$$




$$
\text { where } R E_{-} K_{n}^{k}(t)=\left\{\begin{array}{c}
\text { if } R E_{-} K_{n-}^{k} \text { data } \neq 0, \text { then normal }\left(R E_{-} K_{n_{-}}^{k} \text { data, } \sigma\right) \\
\text { else } 0
\end{array}\right.
$$

where $R E_{-} K_{n}^{k}$ - the element of the mutual exchange vector corresponds to the actual cost of $\mathrm{n}$ partner production which was consumed by k partner, when $n=k$;

$R E_{-} K_{n-}^{k}$ data - the element of the mutual exchange vector, corresponding to the planned cost of $\mathrm{n}$ partner production which was consumed by $\mathrm{k}$ partner when $n=k$;

$\sigma$ - the root-mean-square deviation of the actual cost of the production from the planned one.

2. The amount of network partner inventory $\left(G S_{-} K\right)$ :

$$
\begin{gathered}
G S_{-} K(t+1)=G S_{-} K(t)+G S A_{-} K(t)-G S C_{-} K(t), \\
\text { where } G S A_{-} K(t)=\sum_{k=0}^{n} R E_{-} K_{n}^{k}(t) \text { и } G S C_{-} K(t)=\sum_{k=0}^{n} R E_{-} K_{k}^{n}(t)
\end{gathered}
$$

where $R E_{-} K_{k}^{n}$ - the element of the mutual exchange vector corresponds to the actual cost of $\mathrm{k}$ partner production which was consumed by n partner;

$G S A \_K$ - the inventory receipt to k's network partner;

$G S C_{-} K-$ the inventory consumption by k's network partner.

3. The amount of money available for the network partner exchange $\left(M E_{-} K\right)$ :

$$
M E_{-} K(t+1)=M E_{-} K(t)+M A E_{-} K(t)-M C E_{-} K(t) \text {, where } M A E_{-} K(t)=\sum_{k=0}^{n} R E_{-} K_{k}^{n}+I M_{-} K(t) \text {, }
$$

where $R E_{-} K_{n}^{k}(t)=\left\{\begin{array}{c}\text { if } R E_{-} K_{n-}^{k} \text { data } \neq 0, \text { then normal }\left(R E_{-} K_{n-}^{k} \text { data, } \sigma\right) \\ \text { else } 0\end{array}\right.$ and $M C E_{-} K(t)=\sum_{k=0}^{n} R E_{-} K_{n}^{k}$,

where $D P P_{-} K(t)=\left\{\begin{array}{c}\text { if }\left(M E A_{-} K(t-1)-M C E_{-} K(t-1)\right)<0, \text { then }\left(-\left(M E A_{-} K(t-1)-M C E_{-} K(t-1)\right)<0\right) \\ \text { else } 0\end{array}\right.$

where $M A E \_K$ - the money receipt to k's network partner;

$M C E \_K$ - the money consumption by k's network partner;

$I M \_\bar{K}$ - the inside money use by k's network partner;

$\triangle \overline{P P} K$ - the deficit of k's network partner within the previous period;

$I M U-$ the constant which reflects the inside money use in the system $(0$ - not used, 1 - used $)$.

4. Total used internal money $(I M)$ :

$$
I M(t+1)=I M(t)+I M A(t), \text { где } I M A(t)=\sum_{k=0}^{n} I M_{-} K(t)
$$

where $I M A$ - the amount of inside money introduced into the financial system of the financial network to compensate the lack of cash.

5 . The coefficient of goods provision with money $(K S)$ :

$$
K S(t)=\frac{M F(t)}{M F(t)+G F(t)^{\prime}}
$$

where $M F(t)=\sum_{k=0}^{n} M A E_{-} K(t)+M C E_{-} K(t)$ и $G F(t)=\sum_{k=0}^{n} G S A_{-} K(t)+G S C_{-} K(t)$

where $M F$ - the total cash flow inside the entrepreneurial network;

$G F$ - the total commodity flow inside the entrepreneurial network.

6 . The cooperation coefficient $(K C)$ :

$$
K C(t)=\frac{G F(t)}{G F(t)+U G F(t)}, \text { where } U G F(t)=G F(t)+G S A_{-} 5(t)+G S C_{-} 5(t)
$$

where $U G F$ - the total bidirectional commodity exchange flow with the external environment

In addition to a causal relationship diagram, graphs of the resulting indicators are located on the main screen form of the model. They are presented in Fig. 2.

These graphs are based on the results of the experiment in which inside money was introduced into the system. The first graph shows the dynamics of the amount of money from network partners (ME_n). This indicator reflects the ability of the company to further participation in the exchange. The graph shows that the value of the indicator does not fall below zero in the worst situation. Consequently, all network partners always have the opportunity to exchange. This has a positive effect on the activities of the entrepreneurial network.

The second graph is based on the values of two factors reflecting the state of the system. The coefficient of goods provision with money (liquidity) $(K S)$ characterizes the amount of money circulating in the system with reference to the amount of goods, the standard value is 0.2 . The cooperation coefficient $(K C)$ characterizes the effectiveness of relations and the level of exchange between various participants of the entrepreneurial network, the standard value is 0.3 . Both indicators exceed their normative values at all stages of the entrepreneurial network. This indicates a positive effect of inside money on the business community economy.

The obtained simulation results are in good agreement with actual statistical data and the agent-based model calculation results [10]. 


\section{CONCLUSION}

The offered simulation model is an effective decision-making support tool. But in practice the use of this method causes certain difficulties. The main problem is the impossibility of a simulation experiment conducting without the specialized software - simulation environment. It limits the prospects of this method application, but at the same time it raises the question of external systems integration models.

There are several ways of the simulation model integration with an external information system. The best one is developing a stand-alone java application based on the AnyLogic simulation model. The application obtained in such a way has all the advantages of the classical system dynamic model. However, it is devoid of its main drawback. It can be run on any computer outside the simulation environment. Such an application has broad development prospects. It can become the information system basis, which includes data warehouses, interfaces and other applications and models. Such a system is planned to be implemented as part of further investigations.

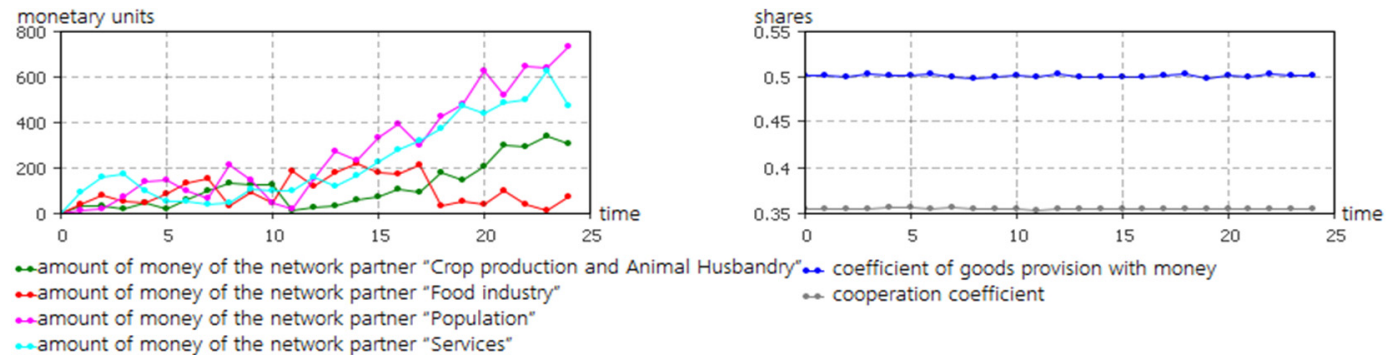

FIGURE 2. Graphs of model resulting indicators.

\section{ACKNOWLEDGMENTS}

Present study was carried out under financial support of the Russian Fund of Fundamental Research grant № 19010-00974 "Experimental institutional models of the autonomy of local communities finances in context of public confidence decreasing in forms of participation in the budget process".

\section{REFERENCES}

[1] J.W. Forrester, "Counterintuitive behavior of social systems", Technology Review, Vol. 73, No. 3, pp. 52-62 (1971).

[2] M.I. Geraskin, Soglasovanie ekonomicheskih interesov v korporativnyh strukturah (IPU RAN, Anko, Moscow, 2005), $293 \mathrm{p}$.

[3] D.Y. Katalevsky, "Upravlenie rostom organizacii na osnove sistemno-dinamicheskogo podhoda", Moscow University Bulletin, Vol. 21, Management (State and Society), No. 4 (2007).

[4] Anna Kolomytseva, Helen Kazakova, and Marina Medvedeva, "Interaction risk assessment in partner entrepreneurial networks", AIP Conference Proceedings 1978, 440013 (2018).

[5] Helen A. Iskra, Marina A. Medvedeva, and Anastasiya V. Apanasenko, "An integrated model of efficiency analysis of companies' network interaction", AIP Conference Proceedings 2040, 050019 (2018).

[6] E.A. Iskra, A.N. Medvedev, A.V. Brodskaya, N.A. Medvedev, "On the Identification of Threats to Information Security Using the Method of Systemic Dynamics", AIP Conference Proceedings 2116, 200026 (2019).

[7] T.A. Ovchinnicova, M.A. Medvedeva, A.A. Taubayev, "Comparative Analysis of Transactions Networks Structure in Local Payment System", AIP Conference Proceedings 2116, 200028 (2019).

[8] Anna Kolomytseva, Helen Iskra, Marina Medvedeva, Juliya Glumova, "Imitation Modeling of Commodity Flows in a Logistic Distribution System", AIP Conference Proceedings 2116, 200030 (2019).

[9] Berg, D.B., Kolomytseva, A.O., Apanasenko, A.V. \& Isaichik, K.F., "Modelling of the Municipality Entrepreneurial Community Functioning Using the Methods of System Dynamics", IFAC-PapersOnLine, Vol. 51, Issue 32, 61-66 (2018); DOI: 10.1016/j.ifacol.2018.11.354.

[10] D. Berg, R. Davletbaev, O. Zvereva, D. Nodjenko, "The model of localized business community economic development under limited financial resources: computer model and experiment", E3S Web of Conferences, Vol. 601001 (2016); doi: http://dx.doi.org/10.1051/e3sconf/20160601001. 